\title{
WHERE DOES TECHNOLOGY FIT IN THE GEOSPATIAL DESIGN AND PLANNING PROFESSIONS?
}

\author{
Carlos J. L. Balsas \\ Ph.D., AICP, Dep. of Geography and Planning \\ 1400 Washington Ave., University at Albany, Albany, NY 12222, U.S.A
}

\begin{abstract}
The societal transformations facilitated in part by geospatial design technological advances have brought new challenges to territorial planning. This paper analyzes the evolution of geospatial design and planning education in the United States by emphasizing the criticality of sustainable transportation planning in facilitating the partial resolution of some of the land use - transportation problems commonly found in environmental justice communities. The paper is in six parts. Part one is a review of geospatial design and planning education in the United States. Part two progresses from education to desired planning skills and a smart cities' framework. Part three is an overview of the dilemmas found in environmental justice communities. Part four explains why technology based on vehicles alone will not create more sustainable transportation. Part five is the case study of an environmental justice community in Albany, New York. Finally, part six makes some concluding remarks.
\end{abstract}

\section{KEYWORDS}

Geospatial Design, Urban and Regional Planning, Smart Cities, Environmental Justice, Sustainable Transportation

\section{INTRODUCTION}

Societal transformations facilitated in part by geospatial design technological advances have brought new challenges to territorial planning (Castells, 1996; Townsend, 2014). The relationship between place and information has been partially strengthened through placemaking and geographical notions of technological progress (Corey and Wilson, 2006). Geospatial design and planning professions such as geography, urban and regional planning, and urban design have had important theoretical and methodological affinities for a long time. The foci of these various disciplines have changed and evolved over the years. Also, new technologies have impacted the practice, scholarship and career paths of many professionals as well as the territory where we live.

The territory has been compressed and flattened, the world has gotten spikier, time and chronology have accelerated, spatiality and governance are ever more interrelated, and the number of professional challenges has increased exponentially. These challenges pose a series of important questions: What kind of scientific relationships should schools nurture? What changes should be made to the curricula? Is there a set path for academic careers? How should schools recruit, promote, deliver and offer education in the geospatial design and planning disciplines? (Balsas, 2000, 2017).

This paper analyzes the evolution of geospatial design and planning education in the United States by emphasizing the criticality of sustainable transportation planning in facilitating the partial resolution of some of the land use - transportation problems commonly found in environmental justice communities. It is argued that millennials (i.e., broadly defined as individuals born in the mid-1980s onwards) comprise a very different generational group than their predecessors; millennials tend to be more environmentally conscious, to drive slightly less, have more access to information, have earned more degrees, see value in their continuing education, and utilize information and communication technologies (ICT) like no previous generation did ever before in history. Such high degree of technological ubiquity has been facilitated by geospatial design and planning technological advancements and it tends to reinforce and perpetuate certain patterns of urban development and societal features (Dixon et al., 2005; Eubanks, 2018). 
The paper is in six parts. Part one is a review of geospatial design and planning education in the United States. Part two progresses from education to desired planning skills and a smart cities' framework. Part three is an overview of the dilemmas found in environmental justice communities. Part four explains why technology based on vehicles alone will not create more sustainable transportation. Part five is the case study of an environmental justice community in Albany, New York. Finally, part six makes some concluding remarks.

\section{GEOSPATIAL DESIGN AND PLANNING EDUCATION}

Geospatial design and planning professions include mostly geography, urban and regional planning, and urban design. Although these disciplines are relatively autonomous, they have some overlaps in terms of theoretical and methodological affinities. New technologies have impacted the practice, scholarship and career paths of many professionals as well as territorial development. Geospatial design and planning require the ability to collect, manipulate, analyze, and present data in tabular, spatial and visual formats.

Of these three disciplines, the planning profession in the United States has evolved from its initial concerns with public health during the reformist period to a role centered more on issues of power, politics, and persuasion (Hoch, 1994; McClendon and Catanese, 1996; Dalton, 2007). Planning education was mostly formalized from the 1950s onwards. Formal training in urban planning was initially proposed in 1957 and the Massachusetts Institute of Technology (MIT) soon thereafter created a doctoral program in planning in 1958 (Rodwin and Sanyal, 2000). The profession's roots can be traced to its geospatial, architecture and landscape architecture traditions. However, the social sciences upbringings of the ecological movement of the Chicago School also provided an impetus to formalize education in planning, mostly from a sociological perspective (Caves and Wagner, 2018). The functionalist investments in planning during the 1930s, which created the planning machinery of maps, zoning codes, tax laws, and other regulations anchored in the Enabling Acts of the 1920 s, would be materialized in subsequent decades.

Planning education has also benefited from the positivist revolution in the 1960s and 1970s when planning developed its emphasis on policy analysis (Friend and Hickling, 2005). Although planning had been represented by the American Institute of Planners (AIP) and the American Society of Planning Officials (ASPO), which were consolidated into the American Planning Association (APA) in 1978, planning education and scholarship only started to receive systematic attention with the creation of the Association of Collegiate Schools of Planning (ACSP) in 1969. ACSP started organizing a separate conference (from the AIP/APA's) in 1981 (Lauria, 2010). Both ACSP's publication outlet and its regular annual conferences aim at the presentation and dissemination of scholarly findings on planning, planning education, and research.

Seminal papers on the core planning competencies and skills in the planning curriculum at both the graduate and undergraduate levels have been published over the years (e.g., Friedmann, 1996; Edwards and Bates, 2011; Greenlee et al., 2015). For a long time, the traditional view of a generalist with a specialization has been challenged with the growth of planning specializations (Balsas, 2015). The core education of planning consists of theory and philosophy of planning, planning history, planning law, planning methods, and planning studios (Friedmann, 1996). The specializations range from land use and transportation to environmental planning, housing, community development, etc.

The debate between planning and urbanism has also continued and even accentuated in recent years mostly due to the rise of New Urbanism (Duany et al., 2001) and Landscape Urbanism (Waldheim, 2016). What and how to teach has changed slightly depending on regional nuances and national sensibilities. Social planning and advocacy planning emerged in the 1970s, partially in response to the civil rights movement and the national environmental programs. Nonetheless, the courses in the core curriculum have been offered consistently throughout most of the country (Frank, 2006). Specializations have grown in number and in depth and breadth of content and methods (Bayer et al, 2010). 


\section{PLANNING SKILLS AND SMART CITIES}

Planning skills include writing, speaking, and analytical competencies in math, drawing, map making, geographical skills, leadership, and decision making, among others (Wilson, 2015). These skills are directly related to planning goals' orientation toward the future, diversity and social justice, equity and equality of opportunity, economic efficiency and environmental sustainability (Banai, 2013; Freestone, 2012; Greenlee et al., 2015). Sandercock (1999) has identified planning literacies fundamental in planning education that range from technical, analytical and multi- or cross-cultural, to ecological, and design.

The ACSP Guide to Undergraduate and Graduate Education in Urban and Regional Planning has been an important document to help individuals know more about program offerings in the United States, specialization requirements, faculty and tuition costs. The Planning Accreditation Board (PAB) was created in 1984, traditionally as a stamp of guarantee on the accredited planning programs, even though a gap between planning theory and practice has always persisted (Baum, 1997; Dalton, 2007). Although PAB is unique to planning programs in North America, the Association of European Schools of Planning (AESOP) has also recently implemented a quality control program along similar lines, although such task may prove much harder given the different European cultures and slightly distinct national planning traditions (Frank et al., 2014).

The interconnectedness of seamless interoperable technological systems is referred to as Smart Cities. Smart cities map and partially recreate the physical world into the virtual environment as a referencing framework for decision making (Eckardt, 2008; Townsend, 2014). The study of new technologies within a smart cities framework have included geographical information systems (GIS); new technopoles; E-government; public participation geographic information systems (PPGIS); intelligent transportation systems (ITS); E-commerce; the use of new technologies to help conserve energy; the deployment of Wi-Fi technology in public spaces via wireless networks; and the digital divide (Horan, 2000; Graham, 2004; Forsyth and Crewe, 2010).

Visualization techniques have also gained prominence due to technological advances and gains in affordability. The sketching and visioning of ideal community conditions has been put forward with before and after illustrations aimed at gaining community support for urban revitalization, site design, neighborhood planning, and streetscape improvements (Kotval, 1996; Kempenaar et al., 2016). For instance, SketchUp is an example of a software utilized for that purpose. Smart cities also reflect a new mentality in planning theory and practice, which to a certain extent, encapsulates a significant change from digital to intelligent development (Corey and Wilson, 2006).

Technological advances are also being appropriated by planning's cognate profession of urban design (Arefi and Al-Dourib, 2016). Ferrandino (2014) has written about how a GIS, as an interdisciplinary pedagogical tool, has also been incorporated in Masters of Public Administration (MPA) programs. Safety and homeland security agencies are also utilizing new technologies to improve safety conditions in cities. Finally, big data collected and utilized to identify trends as well as the Internet of Things (IoT), as the use of linked sensors in a myriad of devices and processes, are two of the latest tendencies in technological advancements (Meyer-Schoenberger and Cukier, 2014).

\section{ENVIRONMENTAL JUSTICE COMMUNITIES}

Environmental justice is the fair treatment and involvement of all people regardless of race, ethnicity, income, national origin, or educational level in decisions pertaining to our natural and built environment and the societal dynamics ensuing from those same governance processes (EPA, 2018). Unfortunately, many minorities and poor communities of color still face a disproportionately higher number of social and environmental issues than socio-economically balanced constituencies in relatively more privileged neighborhoods (Boone and Modarres, 1999; Pastor et al., 2001; Agyeman et al., 2003; Bullard, 2007).

Examples of those injustices resulting partially from inadequate land use - transportation decisions include daily exposure to air and noise pollution from heavy travelled highways, roadways, and industrial activity (Allen et al., 2009), higher likelihood of living in close proximity to contaminated soil and water sources, higher rates of preventable diseases, higher infant mortality rates, and lower life expectancy (Corburn, 2007; Bullard et al., 2014; Carrier et al., 2016). Figure 1. shows a map from the Environmental 
Justice (EJ) Atlas displaying reported environmental conflicts in the United States. Figure 2. shows EPA's RMPs for high-risk industrial and commercial facilities. According to Coming Clean and the Environmental Justice Health Alliance for Chemical Policy Reform (2018: 3) "almost 124 million people (39\% of the U.S. population) live within 3 miles of one of about 12,500 hazardous facilities included in the Environmental Protection Agency's Risk Management Plan (RMP) program.”

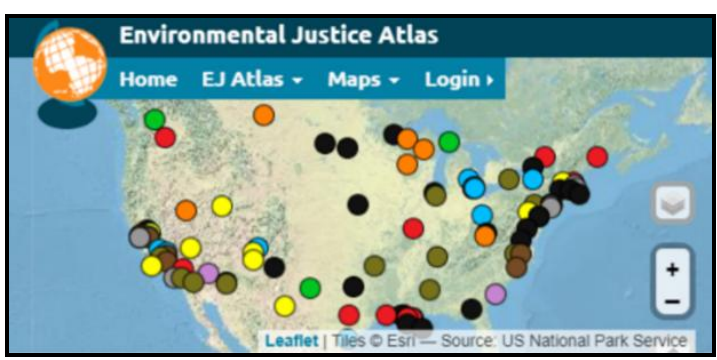

Figure 1. Environmental Justice (EJ) Atlas displaying reported environmental conflicts in the United States (<https:// ejatlas.rg/country/united-states-of-america> May 25, 2019)

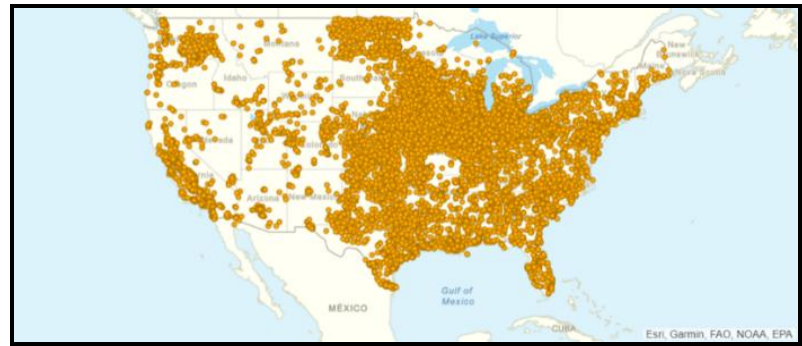

Figure 2. Environmental Protection Agency's Risk Management Plan (RMP) program for high-risk industrial and commercial facilities (<https://ej4all.org/life-at-the-fenceline> May 25, 2019)

In spite of some recent progress leading to the decontamination of polluted brownfield sites in former industrial areas in North American cities, certain regions of the Northeast and Midwest still possess a high number of such sites named by Hollander (2009) as HI-TOADS (i.e., High-Impact Temporarily Obsolete Abandoned Derelict Sites). In certain cases, present situations of environmental racism were created decades ago due to inexpensive land available in places near industrial sites and other LULUs (i.e., local unwanted land uses) (Bolin et al., 2005; Schively, 2007).

The individuals responsible for said land use - transportation decisions may no longer be in the same public office and therefore, it may be difficult to attribute responsibilities to individual decision makers or agencies (Pulido, 1996; Rohe and Freeman, 2001; Krizek and Levinson, 2005). Those who have inherited and are now responsible for managing those complex situations may not have the knowledge or the necessary resources to resolve those environmentally unjust situations (Kennedy, 2015). Therefore, incremental decisions may serve only to perpetuate unjust environmental problems without ever eradicating said state of affairs (Schweitzer and Stephenson Jr, 2007).

Effective environmental advocacy is still urgently needed in many communities throughout the United States, as the Hollywood film "Erin Brockovich" demonstrated in the early 2000s (Banks, 2002). That advocacy has to occur not only with the help of community leaders, elected officials and progressive media outlets, but also with effective and responsible decision making (Kurtz, 2005), which needs to provide resourceful solutions to those most affected by environmental nuisances. Urban and Regional Planning Departments in institutions of higher education ought to engage with those situations and train students in their resolution (Susskind and Amundsen, 1999; Corburn, 2005; Bullard et al., 2014).

\section{SUSTAINABLE TRANSPORTATION PLANNING}

Transportation is critical to the proper functioning of the economy (Goodwin, 1998). The U.S. has an extremely high dependence on automobiles for everyday transportation (Balsas, 2001). However, technology based on vehicles alone will not create more sustainable transportation (Hillman, 2012; Velazquez et al., 2015). More environmental advocacy within a smart cities framework ought to be taken into consideration by those with responsibility for public policy and territorial administration (Evans-Cowley and Manta Conroy, 2006).

With the current societal transformations, the emphasis on environmental problems in North America may have subsided slightly, but perhaps more than ever, there is a great need for pro-active strategies to minimize carbon emissions, to create participatory governance arenas, and to utilize new technologies in addressing the problems created not only by changing demographic patterns and lifestyles, but also by current urbanization trends. The skill sets brought forward by professionals in inter-related areas of study, which have city-region ecosystems and global approaches as their foci, will be increasingly required by those 
in future positions of power in city, regional and national governments as well as in the private and non-profit sectors, including academia (Schon, 1987; Caves and Wagner, 2018; Balsas, 2019).

The federal government, together with many states and non-profit organizations, has only partially attempted to reduce automobile dependence in the United States by incentivizing alternative modes of transportation, such as mass transit, light rail, walking and bicycling (Raco and Flint, 2011). Walking and bicycling in particular have received some attention in recent years in connection with the need to stimulate healthier lifestyles and to reduce the threat of chronicle diseases. Central to those developments was a combination of hard and soft responses to improving transportation infrastructure and the built environment, and to influence the transportation habits of the general population.

It is important to augment the results of previous research and policy programs by multiple stakeholders and to study how best practices can be understood and implemented within a framework of social justice, policy innovation, urban and metropolitan governance, sustainable transportation planning, and smart cities (Banister, 2008; Forsyth, 2012). At the core of such research lies the fundamental dilemma where more endowed communities and agglomerations, usually exclusively car-oriented, are able to provide better infrastructure and to support programs to improve transportation conditions than those with fewer means and resources (Eubanks, 2018) - therefore, perpetuating the resource/poverty gap.

The induced outcomes have led to less sustainable, perhaps contradictory results, which tend to increase automobile dependence instead of reducing car ownership, vehicle miles travelled, gasoline consumption, air and noise pollution, and accidents (Zavestoski and Agyeman, 2015). Guarantying better mobility conditions in communities with fewer means is a social responsibility matter and an opportunity to strengthen living conditions and sustainable livelihoods. Planning schools in the United States ought to pay more attention to these dilemmas in their curricular offerings, research commitments and public engagement responsibilities.

Our research and teaching experience on sustainable transportation planning has led us to believe in the need to strengthen and increase the impact of non-motorized modes of transportation in order to create safer and more livable cities, with lower levels of greenhouse gas emissions, and therefore less propensity to contribute to global climate change (Shay and Khattak, 2010; Balsas, 2019). Market economics aided by community advocacy and public involvement, responsible technological advances, and community-oriented development ought to help accomplish public policy goals that result in safer transportation infrastructure (e.g., road redesigns, bridges and tunnels, bicycle trails and lanes) also in poor communities in the United States and elsewhere. However, those economic measures ought to also emphasize social programs that de-market the automobile and instead attempt to popularize the general use of mass transit and non-motorized transportation for the daily transportation needs of everyone (Portney, 2005; Hajer et al., 2012; Buehler and Hamre, 2015). The next section discusses an alternative town-gown citizen science public engagement in an environmental justice community in upstate New York.

\section{ALBANY'S SOUTH END TOWN-GOWN ENGAGEMENT}

Town-gown applied learning activities constitute a useful methodology in many universities with undergraduate and masters programs in Urban and Regional Planning. Many of those programs involve capstone studios. Often (paying) clients approach the Planning Departments with requests for specific studies. The faculty and student labor is usually perceived as more affordable, more qualified, and under a clout of independence not easily found in professional consulting services provided by firms operating in the marketplace. However, the political economy of host cities tends to privilege certain places and neighborhoods at the expense of others (Soja, 2010; Sassen, 2014). Business districts, commercial corridors, certain residential suburbs, industrial parks, and open space areas tend to receive the most attention. On the other hand, complex planning situations such as environmental justice communities, abandoned ethnic neighborhoods, and areas surrounding landfills required strong epistemological motivation to defray the medium to long-term commitments necessary to turn those places around (Forsyth, 2012; Khan, Moulaert and Schreurs, 2013).

At the beginning of summer 2018, we were alerted to the possibility of helping to provide some planning suggestions to the resolution of a very complex environmental health situation involving the residents at a public housing complex in an environmental justice community in Albany, New York, called Ezra Prentice. Such housing complex is transversed by a busy state arterial road and is located adjacent to a railyard depot 
in the proximity of the Port of Albany (see Figure 3.). The residents, mostly low-income population of color, have been exposed to various types of air pollution generated by heavy roadway traffic and port-related operations such as crude oil transport by rail, among others (Houston, Li and Wu, 2014).
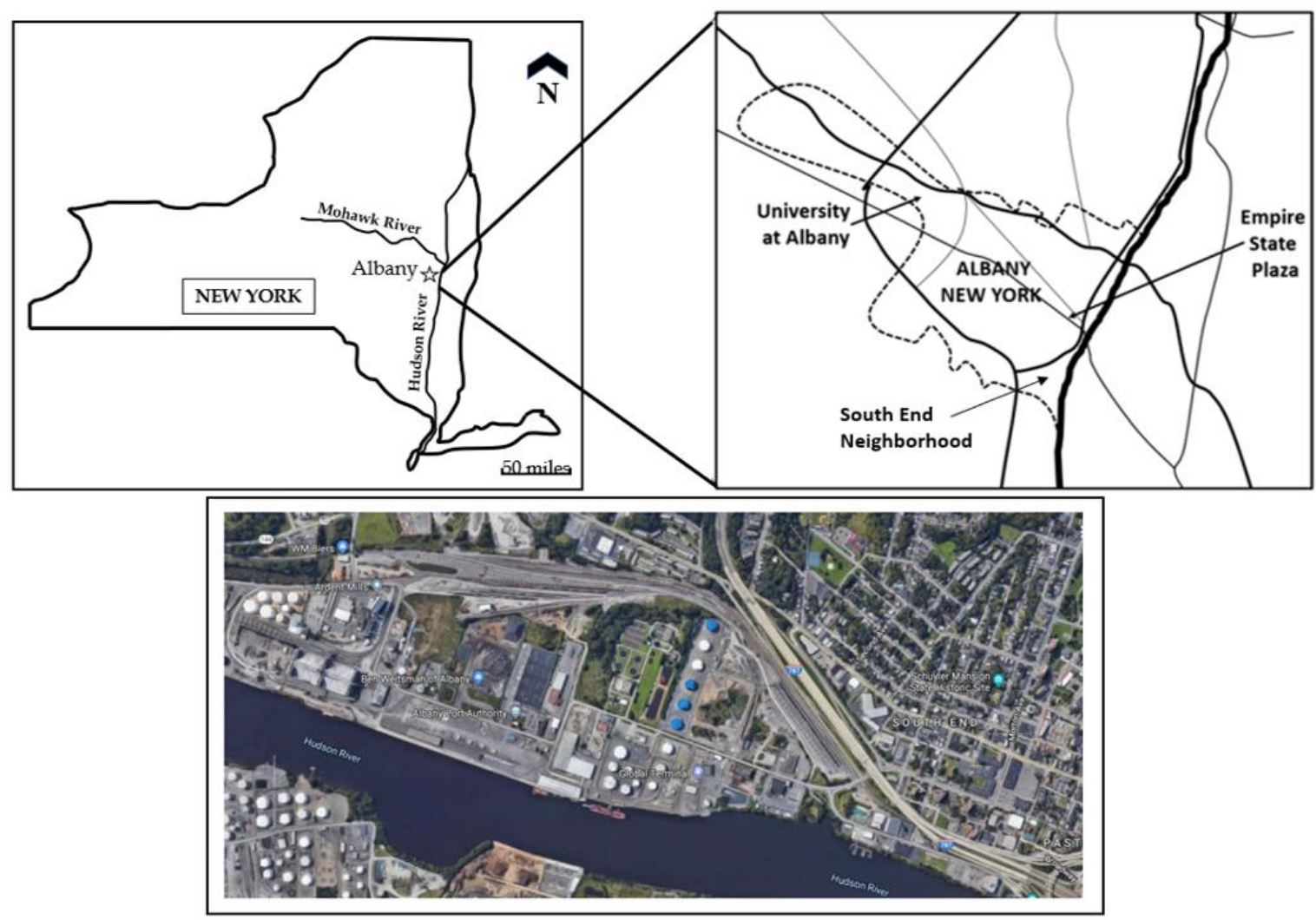

Figure 3. Location of the South End neighborhood in Albany, NY

Severe health problems such as high rates of asthma and other respiratory illnesses have been documented, most likely, in connection with the poor air quality and noise pollution in the area. Prior environmental advocacy by the residents themselves and the leaders of various non-profit organizations in Albany (e.g. AVillage and Radix), since at least 2014, served to alert various elected officials and decision makers to the severity of the problems in the area (Times Union, 2016). In response, in 2017-2018 the NYS Department of Environmental Conservation (DEC) invested about $\$ 500,000$ in equipment and human resources to conduct an air quality study (NYSDEC Division of Air Resources, 2017) (see Figure 4.)
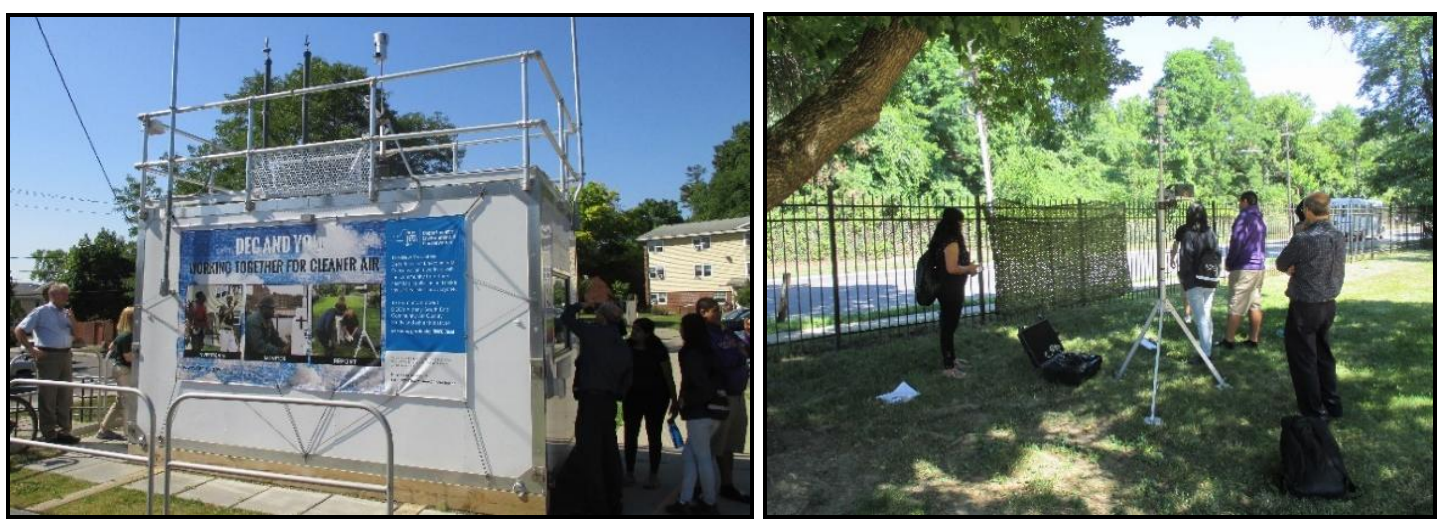

Figure 4. Air monitoring station in the South End neighborhood of Albany | Figure 5. Citizen science public engagement with high school students in June 2018 
Furthermore, the Capital District Transportation Committee (CDTC) has just finalized a study in June 2018 aimed at finding solutions to the heavy truck traffic in the area. This study was conducted to help reduce the number of freight and heavy-traffic vehicles circulating on the main arterial road (Monios, Bergqvist and Woxenius, 2018). In collaboration with scientists from NYS DEC and a group of high-school students from the University at Albany's S.T.E.P. (i.e. Science and Technology Entry Program) we conducted visits to the study site to analyze the possibility of utilizing placemaking urban design strategies, including streetscape improvements and the installation of a greenwall to reduce the encroachment of air pollutants into the housing and playground areas located adjacent to the heavily travelled road through the housing complex. The high school students had meetings with air quality scientists and planners, a guided tour of the air monitoring station, conducted their own air quality measurements, tested the feasibility of installing a greenwall pilot project, and then presented their findings at the 2018 SUNY Albany S.T.E.P. Summer Institute/Smart Scholars Summer Bridge Closing Ceremony on Friday, July 20, 2018 (Figure 5.).

The main objective of this town-gown engagement was to study how the University at Albany could become more relevant to underserved communities in the Capital Region of upstate New York. Collaborations in urban planning and design professions are central to progressive educational models and professional practice. The political economy of recipient university-host communities tends to shape the conception and development of town-gown engagements. A certain dissatisfaction with traditional educational models has led us to explore the applicability of alternative educational paradigms based on citizen science, community engagement and creative arts and culture interventions to resolve structural problems in cities, and in our particular case, in the city of Albany.

We believe that the empathy that resulted from individual and collective social struggles and the affirmation of one's own cultural values on an even playing field, as well as the personal feelings of having been able to accomplish challenging tasks, has serve to motivate us in advancing to higher levels of research performance as well as personal and professional realization. During this town-gown engagement with the S.T.E.P. program we realized that there is power in accomplishing something with the knowledge we had acquired instead of being only the passive recipient (or deliverers) of transmitted knowledge. Although we were not able to reduce - nor to eliminate - the air pollution problem in the South End neighborhood during this short public engagement of various weeks, we are confident that the in-loco visits, the meetings with the scientists and planners, and the brief interactions with the residents revealed the potential of an applied citizen-science research approach. Such approach was mostly aimed at creating higher levels of awareness of the severity of the land use - transport planning problem for the local residents as well as to expose the high school students to geospatial design and planning educational skills. One of the most important lessons learned might well have been the need to better understand the proper siting and management of public housing developments and other sensitive infrastructure in contexts of environmental justice and the eradication of deeply imbedded decades old racist behaviors in urban development.

\section{CONCLUSION}

This paper has analyzed the evolution of geospatial design and planning education in the United States by emphasizing the criticality of sustainable transportation planning in facilitating the partial resolution of some of the land use - transportation problems commonly found in environmental justice communities. Over the past two decades, some of the most recent transformational changes in geosciences have included: Open source (suite of software packages) versus proprietary software (e.g., ESRI); smart communities (interoperability of systems); digital communities; data acquisition, manipulation, analysis and the extraction of useful findings; human, ecological, political, and technological transformations; tools (e.g., GIS, GPS, PPGIS, remote sensing, drones); self-reporting and volunteer programmers helping to produce maps for humanitarian reasons (e.g., Openstreets, and earthquake and tsunami recovery efforts in Haiti and Japan); smart phones and big data, in certain cases making GPS devices obsolete; cloud computing; and wayfinding technology (Rheingold, 2009).

On the other hand, some of the most recent changes in urban and regional planning have included: Renewed emphasis on decision making and technical recommendations; the facilitation and bridging of knowledge with interdisciplinary teams; conflict mediation and consensus building; more encompassing public participation processes; stronger articulation with urban design and architecture; brownfields and 
smart growth principles; climate change adaptability and resilience; disaster emergency preparedness; greater need for visualization technologies; the need to address socio-economic, age, gender and class diversity; E-government; incorporation of geospatial tools; multidisciplinarity in researching non-physical problems (e.g., role of emotions, mental health, environmental nuisances; sedentary lifestyles), and the emergence of 'hybrid' specializations (e.g., landscape urbanism, sustainability, LEED certifications) (Corey and Wilson, 2006).

Two of the most pervasive forces in geospatial design and planning have been the sustainability movement (Hakansson and Asplund, 2002) and the influence of technology (Townsend, 2014). New technologies have had a critical role in shaping digital communities and influencing patterns of urban development. Within a smart cities' framework, new technologies are definitely powerful tools capable of facilitating access to information and of enabling knowledge to be deployed in socially, environmentally, and economically responsive ways. However, it is dangerous to believe that new technologies alone will resolve our complex societal problems (Adams, 1996).

Finally, the South End case study demonstrates the dual potential of a town-gown citizen science public engagement to expose students to complex land use - transportation planning conflicts of siting affordable housing near industrial facilities on one hand, and of using geospatial design and planning skills such as placemaking, air pollution monitoring within a smart cities framework and green infrastructure to partially resolve those same issues, on the other. In closing and from an educational perspective, we demonstrate that geospatial design and planning skills can also be applied to the human utilization and governance decisions of the territory, the creation of more walkable public spaces, and the optimization of public policy decision making processes, especially in environmental justice communities.

\section{REFERENCES}

Adams, J. 1996. “Can technology save us?” World Transport Policy and Practice, Vol. 2, No. 3, pp. 4-17.

Agyeman, J., and Evans, T. 2003. "Toward just sustainability in urban communities: Building equity rights with sustainable solutions." The Annals of the American Academy of Political and Social Science, Vol. 590, pp. 35-53.

Allen, R.W., Davies, H., Cohen, M.A., Mallach, G., Kaufman, J.D., and Adar, S.D. 2009. "The spatial relationship between traffic-generated air pollution and noise in 2 US cities." Environmental Research, Vol. 109, No. 3, pp. 334-342.

Arefi, M., and Al-Dourib, F. 2016. "Exploring pedagogical opportunities between architecture and planning." Planning Theory \& Practice, Vol. 17, No. 1, pp. 72-92.

Balsas, C. 2001. "Cities, automobiles and sustainability." Urban Affairs Review, Vol. 36, No. 3, pp. 429-432.

Balsas, C. 2015. "Sustainable transportation planning, the evolution and impact of a new academic specialization in the USA.” International Journal of Transportation Science and Technology, Vol. 4, No. 1, pp. 1-16.

Balsas, C. 2017. "Blending individual tenacity with government's responsibility in the implementation of US non-motorized transportation planning (NMT)." Planning Practice and Research, Vol. 32, No. 2, pp. 197-211.

Balsas, C. 2019. "Progress and 'acts of god' in the age of climate change virility." International Journal of Global Environmental Issues, Vol. 18, No. 2, pp. 1-19.

Banai, R. 2013. "Cities and regions: The urban sustainability, planning, pedagogy, and technology nexus." Journal of Sustainability Education, No. 5. <http://www.jsedimensions.org/wordpress/wp-content/uploads/2013/06/Reza-BanaifinalproofMay2013-1.pdf> (March 17, 2018).

Banister, D. 2008. "The sustainable mobility paradigm.” Transport Policy, Vol. 15, No. 2, pp. 73-80.

Banks, S. 2002. "The Erin Brockovich Effect.” Environmental Law and Policy Journal, Vol. 26, pp. 219-251.

Baum, H. 1997. "Teaching practice.” Journal of Planning Education and Research, Vol. 17, pp. 21-29.

Bayer, M., Frank, N., and Valerius, J. 2010. Becoming an Urban Planner: A guide to careers in planning and urban design. John Wiley \& Sons, Hoboken.

Bolin, B., Grineski, S., and Collins, T. 2005. "The geography of despair: Environmental racism and the making of South Phoenix, Arizona, USA.” Human Ecology Review, Vol. 12, No. 2, pp. 156-168.

Boone, C.G., and Modarres, A. 1999. "Creating a toxic neighborhood in Los Angeles County: A historical examination of environmental inequity." Urban Affairs Review, Vol. 35, No. 2, pp. 163-187.

Buehler, R., and Hamre, A. 2015. "The multimodal majority? Driving, walking, cycling, and public transportation use among American adults." Transportation, Vol. 42, No. 6, pp. 1081-1101.

Bullard, R. 2007. Growing Smarter. The MIT Press, Cambridge.

Bullard, R., Johnson, G.S., Smith, S.L., and King, D.W. 2014. "Living on the frontline of environmental assault: Lessons from the united states most vulnerable communities." Revista de Educação, Ciências e Matemática, Vol. 3, No. 3, pp. 33-61. 
Carrier, M., Apparicio, P., and Séguin, A.M. 2016. "Road traffic noise in Montreal and environmental equity: What is the situation for the most vulnerable population groups?" Journal of Transport Geography, Vol. 51, pp. 1-8.

Castells, M. 1996. The Rise of the Network Society. Blackwell Publishers, Cambridge.

Caves, R., and Wagner, F. 2018. "Are planning programs delivering what planning students need? Perspectives on planning education from practitioners.” In: Frank, A., and Silver, C. (Eds.) Urban Planning Education: Beginnings, global movement and future prospects. Springer, Cham, pp. 323-337.

Coming Clean and the Environmental Justice Health Alliance for Chemical Policy Reform. 2018. Life at the Fenceline: Understanding Cumulative Health Hazards. <https://ej4all.org/life-at-the-fenceline> (May 25, 2019).

Corburn, J. 2007. "Urban land use, air toxics and public health: Assessing hazardous exposures at the neighborhood scale." Environmental Impact Assessment Review, Vol. 27, No. 2, pp. 145-160.

Corey, K.E., and Wilson, M. 2006. Urban and Regional Technology Planning. Routledge, New York.

Dalton, L. 2007. "Preparing planners for the breadth of practice." Journal of the American Planning Association, Vol. 73, No. 1, pp. 35-48.

Dixon, T., Thompson, B., McAllister, P., Marston, A., and Snow, J. 2005. Real Estate \& the New Economy. Blackwell Publishing, Oxford.

Duany, A., Plater-Zyberg, E., and Speck, J. 2001. Suburban Nation: The rise of sprawl and the decline of the American Dream. North Point Press, New York.

Eckardt, F. 2008. "E-City: From researching the virtual towards understanding the real urban life.” In: Bucher, U., and Finka, M. (Eds.) The Electronic City. BWV Verlag, Berlin, pp. 9-24.

Edwards, M.M., and Bates, L.K. 2011. "Planning's core curriculum: Knowledge, practice, and implementation." Journal of Planning Education and Research, Vol. 31, No. 2, pp. 172-183.

EPA. 2018. "Environmental Justice." < https://www.epa.gov/environmentaljustice> (Accessed July 9, 2018).

Eubanks, V. 2018. Automating Inequality: How high-tech tools profile, police, and punish the poor. St. Martin's Press, New York, NY.

Evans-Cowley, J., and Manta Conroy, M. 2006. "The growth of e-government in municipal planning." Journal of Urban Technology, Vol. 13, No. 1, pp. 81-107.

Ferrandino, J. 2014. "Incorporating GIS as an interdisciplinary pedagogical tool throughout an MPA program." Journal of Public Affairs Education, Vol. 20, No. 4, pp. 529-544.

Forsyth, A. 2012. "Alternative cultures in planning research-From extending scientific frontiers to exploring enduring questions." Journal of Planning Education and Research, Vol. 32, No. 2, pp. 160-168.

Forsyth, A., and Crewe, K. 2010. "Suburban technopoles as places: The international campus-garden-suburb style." Urban Design International, Vol. 15, No. 3, pp. 165-182.

Frank, A.I. 2006. "Three decades of thought on planning education.” Journal of Planning Literature, Vol. 21, pp. 15-67.

Frank, A.I., Mironowicz, I., Lourenço, J., Franchini, T., Ache, P., Finka, M., ..., and Grams, A. 2014. "Educating planners in Europe: A review of 21st century study programmes." Progress in Planning, Vol. 91, pp. 30-94.

Freestone, R. 2012. "Futures thinking in planning education and research." Journal for Education in the Built Environment, Vol. 7, No. 1, pp. 8-38.

Friedmann, J. 1996. "The core curriculum in planning revisited." Journal of Planning Education and Research, Vol. 15, No. 2, pp. 89-104.

Friend, J.K., and Hickling, A. 2005. Planning Under Pressure. Routledge, New York.

Goodwin, P. 1998. "Unintended effects of transport policies." In: Banister, D. (Ed.) Transport Policy and the Environment. E \& FN Spon, London, pp. 114-130.

Graham, S. 2004. The Cybercities Reader. Routledge, London.

Greenlee, A.J., Edwards, M., and Anthony, J. 2015. "Planning skills: An examination of supply and local government demand." Journal of Planning Education and Research, Vol. 35, No. 2, pp. 161-173.

Hajer, M., Hoen, A., and Huitzing, H. 2012. "Shifting gear: Beyond classical mobility policies and urban planning." In: AISSR (Ed.) Keep Moving, Towards Sustainable Mobility. Eleven International Publishing, The Hague, pp.151-178.

Hakansson, M., and Asplund, E. 2002. "Planning for sustainability and the impact of professional cultures." In: Thornley, A., and Rydin, Y. (Eds.) Planning in a Global Era. Ashgate, Burlington, pp. 387-404.

Hillman, M. 2012. "The implications of climate change for the future of the car." World Transport Policy and Practice, Vol. 17, No. 4, pp. 18-29.

Hoch, C. 1994. What Planners Do: Power, politics, and persuasion. APA Planners Press, Chicago.

Hollander, J.B. 2009. Polluted \& dangerous: America's worst abandoned properties and what can be done about them. UPNE, Burlington.

Horan, T.A. 2000. Digital Places: Building our city of bits. ULI-the Urban Land Institute, Washington, D.C.

Houston, D., Li, W., and Wu, J. 2014. "Disparities in exposure to automobile and truck traffic and vehicle emissions near the Los Angeles-Long Beach port complex." American Journal of Public Health, Vol. 104, No. 1, pp. 156-164.

Kempenaar, A., Westerink, J., van Lierop, M., Brinkhuijsen, M., and van den Brink, A. 2016. “"'Design makes you understand"-Mapping the contributions of designing to regional planning and development." Landscape and Urban Planning, Vol. 149, No. May, pp. 20-30. 
Kennedy, M. 2015. Globalizing Knowledge - Intellectuals, universities, and publics in transformation. Stanford University Press, Stanford.

Khan, A., Moulaert, F. and Schreurs, J. 2013. "Epistemology of Space: Exploring relational perspectives in Planning, Urbanism, and Architecture.” International Planning Studies, Vol. 18, No. 3-4, pp. 287-303.

Kotval, Z. 1996. "Telecommunications" Cities, Vol. 16, No. 1, pp. 33-41.

Krizek, K., and Levinson, D. 2005. "Teaching integrated land use-transportation planning." Journal of Planning Education and Research, Vol. 24, pp. 304-316.

Kurtz, H. 2005. "Alternative visions for citizenship practice in an environmental justice dispute." Space Polity, Vol. 9, No. 1, pp. 77-91.

Lauria, M. 2010. “ACSP at 50: Introduction.” The Town Planning Review, Vol. 81, No. 2, pp. i-ii.

McClendon, B.W., and Catanese, A.J. 1996. Planners on Planning: Leading planners offer real-life lessons on what works, what doesn't, and why. Jossey-Bass Inc., San Francisco.

Meyer-Schoenberger, V., and Cukier, K. 2014. Big Data: A revolution that will transform how we live, work and think. First Mariner Books, New York.

Mitchell, W.J. 1996. City of Bits: Space, place, and the infobahn. MIT Press, Cambridge.

Monios, J., Bergqvist, R., and Woxenius, J. 2018. "Port-centric cities: The role of freight distribution in defining the port-city relationship." Journal of Transport Geography, Vol. 66, pp. 53-64.

Murrain, P. 2013. "Landscape Urbanism: Supplement or substitute?" In: Duany, A., and Talen, E. (Eds.) Landscape Urbanism and its Discontents. New Society Publishers, Gabriola Island, pp. 141-158.

NYSDEC Division of Air Resources (2017). "South End Study Progress Update." <https://www.dec.ny.gov/docs/air_pdf/albsouthend011018.pdf> (Accessed July 13, 2018).

Pastor, M., Sadd, J., and Hipp, J. 2001. "Which came first? Toxic facilities, minority move-in, and environmental justice." Journal of Urban Affairs, Vol. 23, No. 1, pp. 1-21.

Phelps, N., and Tewdwr-Jones, M. 2008. "If geography is anything, maybe it's planning's alter ego? Reflections on policy relevance in two disciplines concerned with place and space." Transactions of the Institute of British Geographers, Vol. 33, pp. 366-384.

Portney, K. 2005. "Civic engagement and sustainable cities in the United States." Public Administration Review, Vol. 65, No. 5, pp. 579-591.

Pulido, L. 1996. "A critical review of the methodology of environmental racism research." Antipode, Vol. 28, No. 2, pp. 142-159.

Raco, M., and Flint, J. 2011. "Towards a new politics of urban mobility.” In: Flint, J., and Raco, M. (Eds.) The Future of Sustainable Cities: Critical reflections. Policy Press, Bristol, pp. 243-251.

Rheingold, H. 2009. Smart Mobs: The next social revolution. Basic Books, Cambridge, MA.

Rodwin, L., and Sanyal, B. (Eds.) 2000. The Profession of City Planning: Changes, images, and challenges: 1950-2000. Routledge, New York.

Rohe, W.M., and Freeman, L. 2001. “Assisted housing and residential segregation.” Journal of the American Planning Association, Vol. 67, No. 3, pp. 279-292.

Sandercock, L. 1999. "A portrait of postmodern planning" Plan Canada, Vol. 39, pp. 12-14.

Sassen, S. 2014. Expulsions: Brutality and complexity in the global economy. Harvard University Press, Cambridge.

Schively, C. 2007. "Understanding the NIMBY and LULU phenomena: Reassessing our knowledge base and informing future research." Journal of Planning Literature, Vol. 21, No. 3, pp. 255-266.

Schon, D. 1987. Educating the Reflective Practitioner. Jossey-Bass Publishers, San Francisco.

Schweitzer, L., and Stephenson Jr, M. 2007. "Right answers, wrong questions: Environmental justice as urban research." Urban Studies, Vol. 44, No. 2, pp. 319-337.

Shay, E., and Khattak, A. 2010. "Toward sustainable transport: Conventional and disruptive approaches in the U.S. context.” International Journal of Sustainable Transportation, Vol. 4, pp. 14-40.

Soja, E. W. 2010. Seeking Spatial Justice. University of Minnesota Press, Minneapolis.

Susskind, L., and Amundsen, O. 1999. Using assisted negotiation to settle land use disputes: A guidebook for public officials. Lincoln Institute of Land Policy, Cambridge.

Times Union. 2016. "Editorial: Time to close Prentice.” Times Union, August 21.

Townsend, A. 2014. Smart Cities. W.W. Norton \& Company, New York.

Velazquez, L., Munguia, N., Will, M., Zavala, A., Verdugo, S., Delakowitz, B., and Giannetti, B. 2015. "Sustainable transportation strategies for decoupling road vehicle transport and carbon dioxide emissions." Management of Environmental Quality: An International Journal, Vol. 26, No. 3, pp. 373-388.

Wachs, M. 2000. "Education for transportation planning in a new century." In: Rodwin, L., and Sanyal, B. (Eds.) The Profession of City Planning: Changes, Images and Challenges 1950-2000. Rutgers, New Brunswick, pp. 128-139.

Waldheim, C. 2016. Landscape as Urbanism: A general theory. Princeton University Press, Princeton.

Wilson, M.W. 2015. "On the criticality of mapping practices: Geodesign as critical GIS?" Landscape and Urban Planning, Vol. 142, pp. 226-234.

Zavestoski, S., and Agyeman, J. (Eds.). 2015. Incomplete Streets: Processes, Practices and Possibilities. Routledge, New York. 